\section{TWO CASES OF PRIMARY CARCINOMA OF THE APPENDIX:}

By D.tVID M. GREIG, C.M., F.R.C.S.Edin, SURGEON, DUNDEE ROYAL INFIRMARY; LECTURER ON CLINICAL SURGERY AND SCRGICAL DISEASES OF CHILDREN, ST. ANDREWS UNIVERSITY;
SUKGEON, ROYAL VICTORIA HOSPITAL, ETC.

Primary carcinoma of the appendix is necessarily an uncommon occurrence in any individual surgical practice, hence no justification is required for the publication of isolated cases. Such cases have been collected from time to time by various writers, but as yet have not been numerous enough to justify conclusions as regards sym. ptoms, prognosis, and other valuable clinical data. In both the following cases the patients were operated on in December, 1905. and both are at the present time in perfect healtb, and show no sign of recurrence.

CASE I.

A labourer aged 35 was referred to me by Dr. Lawrence. He was the soungest of twelve, the others being in good bealth. His father died of cancer of the stomach, but his mother was alive and well. Though married he had no family. He had a comfortable home, and was temperate and a moderate smoker. Twenty years previously he seems to have passed through a mild attack of complete syphilis, and four years later he had an attack of bronchitis. These constituted his only previous illnesses.

History of Illness.

Two months previous to my seeing him he supposed he had strained himself at work, for he was seized somewhat suddenly with a pain in the lower part of the abdomen which shot down into the right testicle. He continued at his employment, however, for about a month, the pain gradually getting worse. The taking of food aggravated it; the bowels were very constipated, and he had nain during defaecation. He then consulted Dr. Lawrence, who recognized it as an atypical case of appendicitis, and under whose directions he restricted his diet to fluids, with the use of enemata every other day to relieve the constipation. Dr. Iewren was struck with the fact that the poin continued Dr. Lawren pain continued more severe and more constant than the mildness of the other symptoms would have led one to expect, and it was more irrespechtive of the ingestion of fond. His temperature was lowe than in typical appendicitis. During three weeks of treatmen he improved somewhat, approaching his usual condition of health and becoming almost free from pain. A slight relaxation of diet was allowed, and on the following day the pain returned as violent as ever. 'There was not with this, however, the usual general symptoms of inflammatory disturbance.

Condition on Admission.

On admission to the Dundee Royal Infirmary he looked a strong man, and appeared to be healthy with the exception of slight pulmonary emphysema. He had slight pain at the end of micturition. Locally a little fullness was visible in the right iliac region, with some discoloration and desquamation caused by hot applications. There was some mnscular resistance to palpation and tenderness over the appendix area. An elongated hard swelling was felt a little above and running parallel to Poupart's ligament.

\section{Operation.}

On December 13th, 1905, under chloroform anaesthesia, the caecal region was exposed by the usual incision. The appendix was found to be imbedded in an inflammatory mass attached along' the line of Poupart's ligament, and, dipping down into the pelvis, was attached to the bladder. To facilitate manipulation it was necessary to make a median incision to supplement the original one, and the mass was dissected out, the stem of the original one, and the mass was dissected out, the stem of the appendix being treated in the usual way. The operation, which was an anusually difficult one on account of the density raw surface from which the inflammatory mass had been raw surface from which the inflammatory mass had been it a drainage tube from either wound.

\section{After-History}

The wounds were dressed on the following day and daily thereafter until the removal of the tubes, the suprapubic one being removed on the fifth and the iliac on the eighth day after the operation. The wounds healed without any further difficulty, and the patient went home on January 20th. After his discharge from hospital I saw him occasionally until he went to America in the spring of 1907 . While there he retained 12 st. $10 \mathrm{lb}$, a weight he had never previously attained. His 12 st. $10 \mathrm{lb}$., a weight he had never previously attained. His oucasionally had pain about the region of the right kidney, but nothing abnormal could be made out in connexion with that nothing abnormal could be made out in connexion with that argan. He still is, in excellent health and condition. The cicatrices were strong and showed no yielding, though he wore no belt. An occasional pain about the right loin is conoplained of, but examination is entirely negative.

Description of Parts Removed.

Prolessor Sutberland, who examined the growth for me, Proles that the lesion was quite definitely cancerous, marked inflammatory new formation in the parts around. It had originated in the epithelium of the tubules, assumed in places a glandular disposition, but, losing this again, comported places a glandular disposition, but, losing this again, comported whatever that it was not an ordinary cylinder-celled epithelial carcinoma of the intestine.

CASE II.

For permission to publish the second case I am indebted to Dr. R. C. Buist.

The patient was a married woman, aged 36, who had been sent into his ward on account of uterine tibroids, for which he did a hysterectomy. During the inspection of the parts after the completion of the hysterectomy it was noticed that the free the completion of the hysterectomy it was noticed that the free end of the appendix was the seat of what appeared to be a plumsized cyst without any adhesions or any inflammatory adjuncts whatever. The appendix was removed in the usual way. Professor Sutherland examined the tumour removed with the appendix and found that it was cancerous, the microscopic examination showing a cylinder-celled carcinoma. The patient made an uninterrup

These two cases fall into very different categories, and for clinical purposes hardly deserve to be classed together. The former proves the danger, the latter merely demonstrates the possibility of the existence, of primary carcinoma of the appendix. In the former the appendicitis, with its pain and its surrounding inflammation, was the dominant symptom; in the latter no symptoms had arisen. Both the patients were about the same age, rather on the young side for malignant disease of the bowels. The variety of carcinoma found in primary affection of the appendix appears to be most commonly of the cylinder-celled variety, and such was present in the latter case. It is much rarer, indeed, to find the appendix the seat of an alveolar carcinoma, and this the pathological examination showed the tumour to be in the former case.

\section{fftemuranda:}

\section{MEDICAL, SURGICAI, OBSTETRICAL.}

HEREDITARY TRANSMISSION OF SQUINT.

THE following particulars of a case may prove of interest : On Thursday, September 23rd, a girl, aged 11, attended Mr. Sydney Stephenson's out-patient department at the Queen's Hospital for Children with a convergent squint of the right eye which measured 35 degrees on the perimeter, the lateral movements of the eye being unimpaired. Right vision $\frac{5}{18}$ partially, left vision $\frac{5}{12}$. It was noticed that the mother also had a convergent fquint of the right eje measuring 25 degrees on the perimeter, and there was defective outward movement of the right eye.

On inquiring into the case it was found that on the motber's side the following members of the family had a

M. Male.

convergent squint: Six out of her seven children-that is, all her children except the youngest, aged 2 months-the mother and her two brotbers, her father and two of his brothers, and her grandfather.

The chart, which was kindly got out for me by the sister in charge of the out-patients, gives the tree of this interesting case of hereditary transmission of squint.

Acton Vale, W.

Eriest E. B. Landon, M.R.C.S. 